\title{
AVALIAÇÃO DE DESEMPENHO DE PAVERS INTERTRAVADO PRODUZIDOS COM REJEITOS GERADOS NOS DESDOBRAMENTOS DE ROCHAS ORNAMENTAIS
}

\author{
Intervaled pavers performance evaluation produced with rejects generated in \\ ornamental rock developments
}

Thais Cristina Bastos de ARAUJO' ${ }^{1}$, Harerton DOURADO ${ }^{2}$

Recebido em 18 de setembro de 2019; aceito em 12 de abril de 2020; disponível on-line em 04 de junho de 2020.

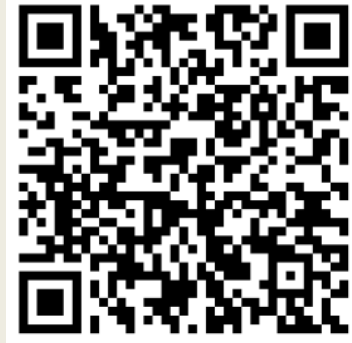

PALAVRAS CHAVE:

Pavers;

Lama abrasiva;

resistência;

pavers intertravado;

\section{KEYWORDS:}

Pavers;

Abrasive sludge;

resistance;

interlocked pavers;

RESUMO: O presente trabalho teve por finalidade estudar a resistência à compressão dos pavers produzidos com rejeitos gerados no desdobramentos de rochas ornamentais. Foram elaborados diversos traços com diferentes porcentagens sendo substituído parte do pó de pedra por lama abrasiva. Os estudos mostraram que a adição da lama abrasiva na confecção dos blocos apresentou um resultado satisfatório, aumentando a resistência à compressão, os traços Padrão, 1 e enquadraram-se nas Normas Australiana e Africana, já o Traço 3 e o Traço 4 alcançaram além das Normas Australiana e Africana também a Norma Brasileira, que exige no mínimo $35 \mathrm{MPa}$ para tráfego de pedestres, veículos leves e veículos comerciais de linha.

ABSTRACT: The aim of this paper was to study the compressive strength of pavers produced with tailings generated in the development of ornamental rocks. Several strokes with different percentages were elaborated and part of the stone dust was replaced by abrasive mud. Studies have shown that the addition of abrasive sludge in the making of the blocks has shown a satisfactory result, increasing the compressive strength, the Standard strokes, 1 and fit the Australian and African Standards, while the Trace 3 and Trace 4 reached beyond Australian and African Standards also the Brazilian Standard, which requires at least 35MPa for pedestrian, light vehicle and commercial line traffic.

* Contato com os autores:

${ }^{1}$ thaiscristinabastosdearaujo@outlook.com (ARAUJO, T. C. B )

Engenharia Civil, Bacharel, aluna, Faculdades Integradas de Aracruz (Faacz).

2 harerton@fsjb.edu.br (DOURADO, H)

Engenharia Mecânica, Doutor, orientador, Universidade Federal do Espírito Santo (Ufes) 


\section{INTRODUÇÃO}

A pavimentação intertravada ocorre quando os blocos de concreto são encaixados entre si no pavimento, distribuindo as tensões e os carregamentos entre as peças, em um comportamento solidário (AGUILAR, 2016).

Nos dias de hoje, o uso de blocos intertravados de concreto para pavimentação vem aumentando, sendo utilizados essencialmente em praças, ruas, parques, pátios e calçadas. Na cidade de Blumenau, Santa Catarina, há um exemplo claro em algumas obras realizadas no município, como é - caso da rua 15 de novembro, a qual foi totalmente revitalizada (ABCP, 2012). O avanço da utilização de pavers intertravados é devido às suas características, entre elas estão a excelente resistência, durabilidade, facilidade de execução, baixo custo de manutenção, reutilização das peças e capacidade de drenagem. Após a execução da pavimentação a liberação do tráfego de pessoas e veículos é imediata, pois não há necessidade de aguardar o tempo de cura; a mão de obra não precisa ser especializada, devido a facilidade de assentamento das peças, além de possuir uma diversidade de cores e formatos.

A estrutura do pavimento vai depender da intensidade do tráfego sobre o pavimento e das características do solo que compõe o subleito. (WIEBBELLING, 2015). Essas estruturas podem ser constituídas pelas seguintes camadas: subleito, sub-base, base, camada de assentamento e camada de rolamento.

Diferentes tipos de materiais podem ser usados e reaproveitados para a produção dos pavers, como resíduos de pneus e resíduos de construção civil/demolição entre outros. Estudos realizados por Lima (2010) e Li et al. (2013) com o intuito de aproveitamento da lama abrasiva como insumo na fabricação de novos produtos, observou que a incorporação deste rejeito na produção de cimento é uma opção viável, uma vez que o resíduo apresenta na composição a maioria dos constituintes químicos do cimento, mas em proporções distintas.
A lama abrasiva é o resíduo gerado pelo beneficiamento de rochas ornamentais nos processos de corte e polimento. Este material apesar de não conter um componente perigoso em sua composição, o descarte incorreto do material pode gerar vários riscos para o meio ambiente. Isso porque, quando despejada diretamente em um recurso hídrico, poderá ocasionar seu assoreamento e turbidez que afetam diretamente a biota local, além de contaminar o lençol freático, contaminar o solo, poluir a atmosférica, desfigurar a paisagem e causar danos à saúde.

Visando isto, a confecção dos pavers intertravados de concreto com aplicação da lama abrasiva tem como intuito a utilização desse resíduo de forma inerte, com finalidade de diminuir os custos dos blocos e sobretudo destacase a alternativa de reutilização desse material de forma verde contrapondo-se seu descarte sem qualquer benefício ao meio ou ao homem.

Os blocos devem atender a NBR 9781:2013 (ABNT, 2013), que tem por objetivo fixar os requisitos exigíveis para confecção de blocos, cumprindo os valores devidos para os ensaios de compressão.

A estrutura do pavimento vai depender da intensidade do tráfego sobre o pavimento e das características do solo que compõe o subleito. (WIEBBELLING, 2015). Essas estruturas podem ser constituídas pelas seguintes camadas: subleito, sub-base, base, camada de assentamento e camada de rolamento.

A lama abrasiva é o resíduo gerado pelo beneficiamento de rochas ornamentais nos processos de corte e polimento. Este material apesar de não conter um componente perigoso em sua composição, o descarte incorreto do material pode gerar vários riscos para o meio ambiente. Isso porque, quando despejada diretamente em um recurso hídrico, poderá ocasionar seu assoreamento e turbidez que afetam diretamente a biota local, além de contaminar o lençol freático, contaminar o solo, poluir a atmosférica, desfigurar a paisagem e 
causar danos à saúde.

Visando isto, a confecção dos pavers intertravados de concreto com aplicação da lama abrasiva tem como intuito a utilização desse resíduo de forma inerte, com finalidade de diminuir os custo dos blocos e sobretudo destacase a alternativa de reutilização desse material de forma verde contrapondo-se seu descarte sem qualquer benefício ao meio ou ao homem.

Os blocos deveram atender a NBR 9781: 2013 Peças de concreto para pavimentação Especificação e métodos de ensaio, que tem por objetivo fixar os requisitos exigíveis para confecção de blocos, cumprindo os valores devidos para os ensaios de compressão e abrasão.

\subsection{OBJETIVOS}

O objetivo geral consiste em analisar o desempenho dos pavers intertravados elaborados com lama abrasiva, através do ensaio de resistência à compressão.

\section{REFERÊNCIAL TEÓRICO}

\subsection{HISTÓRIA DA PAVIMENTAÇÃO}

\subsubsection{No Exterior}

Percorrer a história da pavimentação nos remete à própria história da humanidade, passando pelo povoamento dos continentes, conquistas territoriais, intercâmbio comercial, cultural e religioso, urbanização e desenvolvimento. Como os pavimentos, a história também é construída em camadas e, frequentemente, as estradas formam um caminho para examinar o passado, por esse motivo serem uma das primeiras buscas dos arqueólogos nas explorações de civilizações antigas. (BERNUCCl et al., 2006)

Com o decorrer dos anos, os povos sentiram a necessidade de erguer caminhos, atalhos e estradas, com a finalidade de vencer as grandes distâncias que existiam entre diferentes povoados, para então conseguir estabelecer uma comunicação entre eles. (FIORITI, 2007)

Os etruscos dominaram grande parte da Itália durante o período de 800-350 aC e suas estradas se tornaram o modelo para o desenvolvimento das estradas romanas. De fato, quando nos referimos a estradas romanas, devemos creditar os etruscos com sua invenção: eles parecem ser os primeiros. Para se juntar a locais distantes com um longo andar, antes disso, as estradas eram apenas caminhos bem trilhados. As estradas etruscas foram cortadas profundamente no solo rochoso a uma profundidade de 2,5m e uma largura de $3 \mathrm{~m}$. Eles foram pavimentados e pode ter incluído sulcos artificiais para guiar carrinhos com derivações para ultrapassagem e estacionamento. As ruas da cidade etrusca tinham 15 metros de largura e incluíam degraus para impedir que pedestres caminhem na superfície molhada da rua. (KNAPTON, 1996, p. 17)

De acordo com Wiebbelling (2015), os Romanos receberam muitos conhecimentos dos Etruscos, colaborando assim para a amplificação do seu império. As vias romanas foram construídas conforme a disponibilidade de materiais, clima e topografia, e eram construídos de acordo com a sua importância.

Os revestimentos normalmente eram feitos com solos arenosos, misturado com pedras naturais, nas ruas mais movimentadas eram utilizadas pedras talhadas manualmente. (WIEBBELLING, 2015)

Os Romanos foram os responsáveis por edificar as famosas ruas da Idade Média, sendo algumas delas, a Watling Street, Ermine Street e Fosse Way Street. Para a construção dos caminhos, os romanos classificavam os tipos de areia, como as de rio, as extraídas dos canais e a do solo natural. Eles misturavam os três tipos de areia juntamente com cal ou calcário, formando uma argamassa e em seguida era inserido o seixo rolado ou pedras de mão espalhadas sobre o caminho. (CRUZ, 2003) 
Wiebbelling (2015), afirma que, ao decorrer dos anos, com o aumento da população e consequentemente do comércio, foi necessário utilizar mais camadas de revestimentos, para suportar as cargas.

O procedimento para a elaboração dos tipos de peças para pavimentação podem ser elaborados em quatro tipos de materiais, Wiebbelling (2015) descreve os elementos como sendo,

[...] blocos de tijolos de argila, pedras talhadas, blocos de tijolos de madeira e pré-moldados de concreto. Os primeiros relatos do uso de betume em pavimentação e tijolos de argila em revestimento foi há aproximadamente 5.000 anos, na Mesopotâmia. Os tijolos eram colocados sobre uma camada de betume com a finalidade de proporcionar aderência ao tijolo, apesar disso, os tijolos não tinham grande resistência, em consequência ao desgaste superficial causado pela ação do tráfego.

\subsubsection{No Brasil}

No Brasil, o trecho da Estrada Real em Paraty - o Caminho Velho, atualmente é o maior trecho calçado e consistentemente preservado de toda a rota. São $8.700 \mathrm{~m}$ calçados em pedra seca, alguns trechos no século XVIII outros, no século XIX, quando houve manutenção e reforma geral. Os trechos do século XVIII são constituídos por pedras mais toscas, mais arredondadas e menos resistentes. Já no século XIX o calçamento foi confeccionado por rochas de formato mais retilíneo, obtidas por explosão controlada, as maiores medindo mais de um metro de lado, entremeadas por areia grossa e outras menores que dão uniformidade ao conjunto. A face superior é mais regular. Têm em média 20 centímetros de altura, mas pedras enormes também foram utilizadas, criando momentos impressionantes ao longo do percurso. (MATTOSO, 2009)

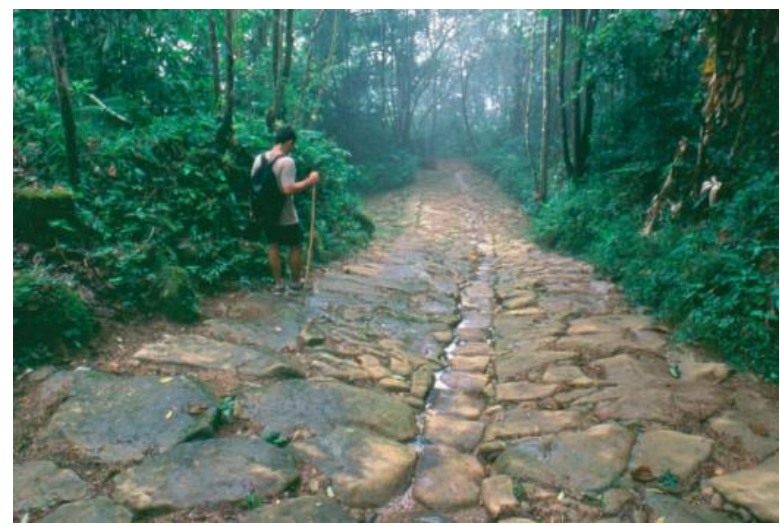

FIGURA 1:M.S. - Caminho do Ouro, parte IV - sítio da Cachoerinha.

FONTE: MATTOSO, 2009.

Ainda conforme Mattoso (2009), a construção deste trecho com o uso de pedras foi necessária devido à alta pluviosidade da Serra conciliada com declives evidenciados, por esse motivo se tornou transitável após o calçamento, sendo ainda uma das únicas vias existentes.

\subsection{PAVIMENTAÇÃO INTERTRAVADA}

Pavimento é a estrutura construída sobre a terraplanagem e destinada, econômica, técnica e simultaneamente a suportar e distribuir os esforços verticais provenientes do tráfego, melhorar as condições de rolamento quanto ao conforto e segurança, resistir ao desgaste. A estrutura do pavimento que se constrói pode variar quanto a espessura, aos materiais utilizados e também com a própria função que a via poderá exerce.

O pavimento é composto por camadas sobrepostas de diferentes materiais compactados a partir do subleito, adequada para atender estruturalmente e operacionalmente o tráfego, de forma durável e ao mínimo custo possível, considerando o serviço de manutenção e reabilitação obrigatórias (BALBO, 2007).

A estrutura do pavimento intertravado é caracterizada pelo revestimento em blocos, com alta durabilidade e resistência, assentados sobre 
uma camada de areia, a base, a sub-base e o subleito. A figura a seguir mostra uma seção transversal característica da estrutura de uma pavimentação.

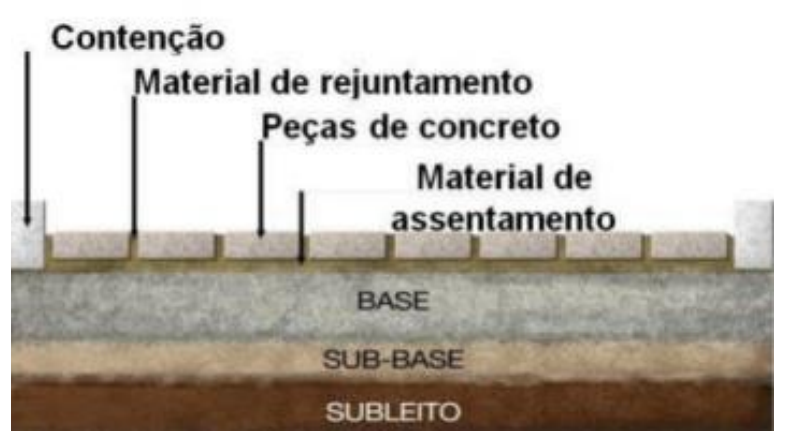

FIGURA 2: Estrutura do pavimento flexível FONTE: ABCP (2001)

Intertravamento é a resistência obtida pelos blocos de se deslocarem individualmente, em relação a seus vizinhos, para atingir esse objetivo é indispensável a utilização de contenção lateral que intertrava o bloco impedindo o deslocamento lateral na camada de rolamento e a areia de selagem que é a junta preenchida por areia com a função de transferir os esforços entre os blocos de concreto, para que suportem as cargas solicitantes. Assim o intertravamento é primordial para garantir um bom funcionamento e durabilidade do pavimento (ABCP, 2010).
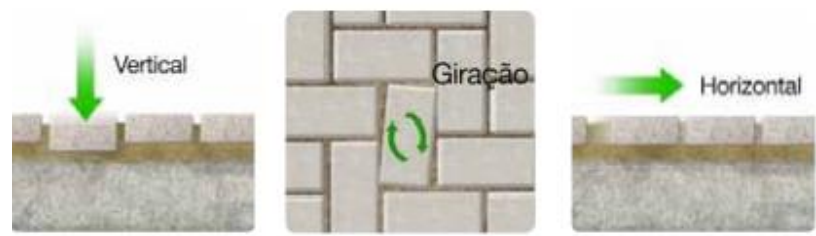

FIGURA 3: Funcionalidade do Intertravamento FONTE: ABCP, 2010.

\subsection{BLOCOS INTERTRAVADOS DE CONCRETO}

Conforme Amadei (2011) os blocos têm conquistado espaço no mercado gradativamente, devido às muitas vantagens que esse produto oferece, destacando a facilidade de assentamento, a liberação para o tráfego rapidamente, a acessibilidade às redes subterrâneas e a praticidade na manutenção. Ainda deve ser salientada a permeabilidade que esse pavimento proporciona, auxiliando na drenagem urbana.

O bloco intertravado de concreto possui alta durabilidade, superfície regular e antiderrapante, proporcionando conforto ao usuário; menor consumo de iluminação pública devido à sua coloração mais clara; menor absorção de energia, minimizando o efeito de ilha de calor. Além de a instalação ser fácil, as peças são reaproveitadas em caso de necessidade de manutenção ou intervenção de concessionárias de energia, gás, telefonia, entre outros. Quando necessário, o pavimento intertravado também pode ser projetado para ser permeável, colaborando para que a água superficial retorne ao lençol freático. Para essa função é necessário um projeto específico das camadas de base, que devem ter porosidade em torno de $30 \%$.

\subsubsection{Tipos de Blocos Intertravados de concreto}

Os pavers de concreto podem ser fabricados de vários formatos e cores que consegue variar a estética quando combinado, é essencial que 0 bloco quando assentado proporcione uma boa distribuição de cargas em sua combinação. A NBR 9781:2013 agrupa esses blocos em quatro tipos diferentes, a saber:

Tipo I - Pavers semelhante ao formato retangular, sua relação de comprimento/largura seja igual a dois, que seus quatro lados se encaixem podendo ser assentadas em fileiras ou em espinha de peixe.

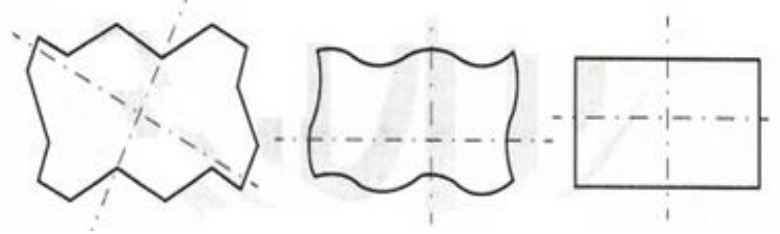

FIGURA 4: Exemplos de peças de concreto do tipo I FONTE: NBR 9781:2013.

Tipo II - Paver de formato único, diferente do formato Tipo I e que só podem ser assentadas em fileiras. 


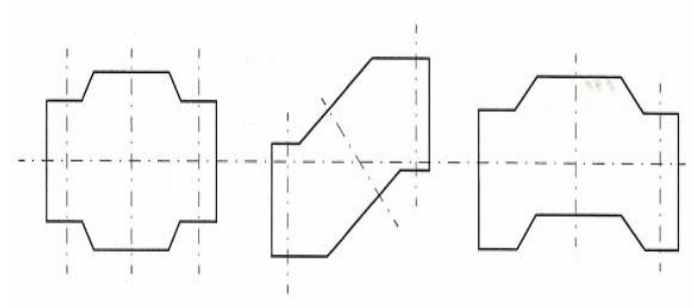

FIGURA 5: Exemplos de peças de concreto do tipo II FONTE: NBR 9781:2013.

Tipo III - Paver de peso superior a $4 \mathrm{~kg}$ de formatos geométricos específicos, como trapézios, hexágonos, triedros etc.
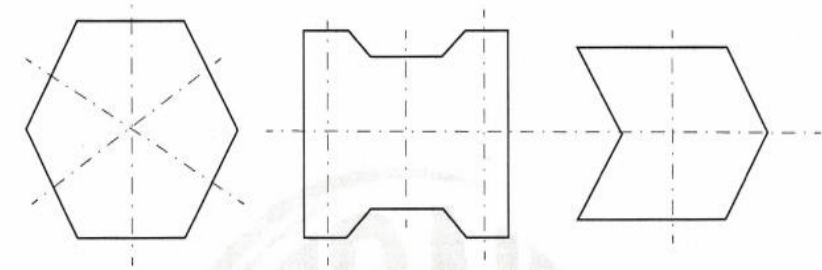

FIGURA 6: Exemplos de peças de concreto do tipo III FONTE: NBR 9781:2013.

Tipo IV - Pavers de diferentes tamanhos que possam se agrupar, e uma única peça com juntas falsas, que em sua montagem empregue um ou mais padrões de assentamento.

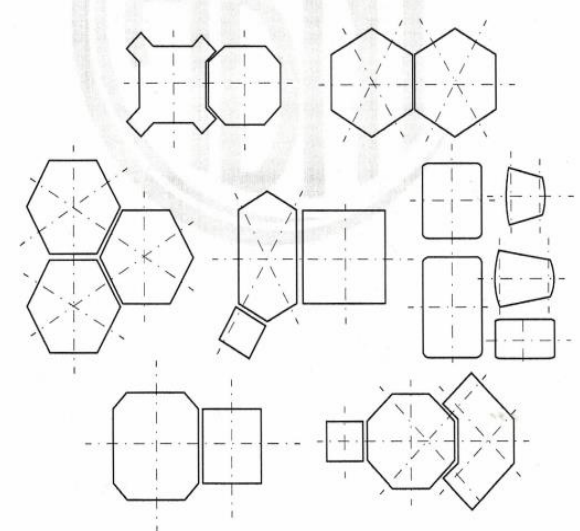

FIGURA 7: Exemplos de peças de concreto do tipo IV FONTE: NBR 9781:2013.

\subsection{LAMA ABRASIVA}

A lama abrasiva, também chamada de lama da serragem possui característica granulométrica de $18,57 \%$ de material retido na peneira $\mathrm{n}^{\circ} 30(0,6 \mathrm{~mm})$ e $51,48 \%$ na de $0,075 \mathrm{~mm}$ $\left(n^{\circ}\right.$ 200) (COELHO et al.,2007). De acordo com Leite (2006) a composição da lama é feita a partir da junção de alguns componentes, sendo eles: cal, água, pó de pedra, aço/lâmina resultante da granalha, sendo cada um responsável por uma função específica. Assim, sua variação ocorre apenas quando a qualidade ou tipo de componente é trocado.

Além desses compostos, pode-se destacar o pH básico girando em torno de 9 a $12 \mathrm{e}$ a coloração do mesmo, pois quando o resíduo apresenta-se branco, significa possuir os elementos ferro, silício e cálcio em maior proporção; para o estágio cinza claro, predomina a cal associada a restos de rocha; e na fase cinza escuro destacam-se 9 fragmentos de rochas graníticas somados a altas quantidades de silício (SILVA, 1998 apud BRANDÃO; RIBEIRO, 2007).

\subsubsection{Composição química média de lama abrasiva no Espírito Santo}

A Tabela 1 mostra a composição química média de lama abrasiva no desdobramento de teares no Estado do Espírito Santo.

\subsubsection{Preocupação das indústrias com o descarte do material produzido no desdobramento de rochas ornamentais}

De acordo com Souza et. al. (2006) o sistema de desdobramento de blocos de granito

\begin{tabular}{|c|c|c|c|c|}
\hline & Cal & Água & Granalha & Pó de Pedra \\
\hline $\begin{array}{c}\text { Porcentagem em } \\
\text { peso (\%): }\end{array}$ & 1,2 & 33,4 & 20,1 & 45,3 \\
\hline $\begin{array}{c}\text { Porcentagem em } \\
\text { volume (\%): }\end{array}$ & 1,2 & 66,0 & 4,2 & 28,6 \\
\hline
\end{tabular}


para a produção de chapas gera uma quantidade significativa de rejeitos produzindo a lama abrasiva, $20 \%$ a $25 \%$ dos blocos.

Este resíduo pode ser utilizado em outras atividades, como tijolos, blocos estrutural, concreto, telhas e pavers que é a proposta do presente trabalho, como forma de aproveitamento deste tipo de rejeito industrial e a redução do impacto ambiental.

Sendo assim, as empresas no ramo de rochas ornamentais começaram a se preocupar com o destino de seus resíduos, devido a cobrança cada vez maior e eficaz por parte dos órgãos ambientais, através de sua fiscalização e legislação, fizeram com que os empresários passassem a preocupar com os impactos ambientais gerados pelas diversas atividades desenvolvidas pelo setor.

A grande maioria dos rejeitos produzidos pelas indústrias são lançados em lagoas de decantação e aterros. Além da contaminação direta dos aquíferos superficiais, os resíduos descaracterizam a paisagem e preocupam as autoridades públicas, órgãos sanitários e a população localizada no entorno das serrarias e áreas da extração.

\subsection{RESISTÊNCIA À COMPRESSÃO}

A resistência à compressão é alcançada dividindo-se a carga de ruptura, expressa em newtons $(\mathrm{N})$, pela área de carregamento, expressa em milímetros quadrados $\left(\mathrm{mm}^{2}\right)$, multiplicando-se o resultado pelo fator $p$, função da altura da peça. Portanto, a resistência a compressão é determinada a partir ensaios com máquinas de testes de compressão.

Os pavers intertravados de concreto devem atender as especificações conforme orienta a NBR 9781:2013 na Tabela 2.

\section{TABELA 2: Resistência característica à compressão.}

Resistência característica à compressão

\section{Solicitações}

\section{$\left(f_{p k}\right)$ aos 28 dias}

$\mathrm{MPa}$

\begin{tabular}{ll}
\hline Tráfego de pedestres, veículos leves e & $\geq 35$ \\
veículos comerciais de linha & \\
\hline $\begin{array}{l}\text { Tráfego de veículos especiais e solicitações } \\
\text { capazes de produzir efeitos de abrasão } \\
\text { acentuados }\end{array}$ & $\geq 50$ \\
\hline
\end{tabular}




\subsection{REQUISITOS TÉCNICOS INTERNACIONAIS}

\subsubsection{Norma Australiana}

De acordo com Bittencourt (2012), a norma Australiana AS/NZS 4456.4:2003 define que os valores mínimos exigidos para a resistência a compressão dos pavers são de $25 \mathrm{Mpa}$ para veículos leves e de $60 \mathrm{Mpa}$ para veículos especiais e para ciclovias e estacionamento os valores dão de $15 \mathrm{Mpa}$.

\subsubsection{Norma Africana}

A norma da África do Sul SANS 1058:2009 define que os valores mínimos exigidos para a resistência a compressão dos pavers são de 25 Mpa para veículos leves e de 35 Mpa para veículos pesados (BITTENCOURT, 2012).

\subsubsection{Normas Americana e Canadense}

Conforme Bittencourt (2012) os primeiros estudos sobre o pavers foram feitos pelo ICPI (Instituto de Pavimento de Peças PréMoldadas de Concreto), na década de 1990. A partir destes estudos foram criadas duas normas: a americana ASTMC936:1996: Standard specification for solid concrete interlocking paving units, e a canadense CSAA23.2-95:1995: Precast concrete pavers.

Os requisitos da norma americana para resistência à compressão é de $\geq 55 \mathrm{Mpa}$ tanto para a média quanto para os valores individuais, já a norma canadense é de $\geq 50$ Mpa para média e $\geq$ 45 para valores individuais dos pavers.

\section{METODOLOGIA}

\subsection{CARACTERIZAÇÃO DOS MATERIAIS}

\subsubsection{Determinação da Composição Granulométrica}

\subsubsection{Determinação da Composição}

Granulométrica - Agregado Miúdo Areia

A granulometria do agregado miúdo areia foi obtida através de peneiramento mecânico

obedecendo à norma NBR NM 248:2003 e NBR 7211. A figura a seguir mostra a curva granulométrica da areia onde ela se enquadra nos limites da zona utilizável para agregados miúdos.

A Tabela 3 apresenta características físicas da areia e sua classificação. A areia possui módulo de finura de 2,22 e dimensão máxima de $2,38 \mathrm{~mm}$.

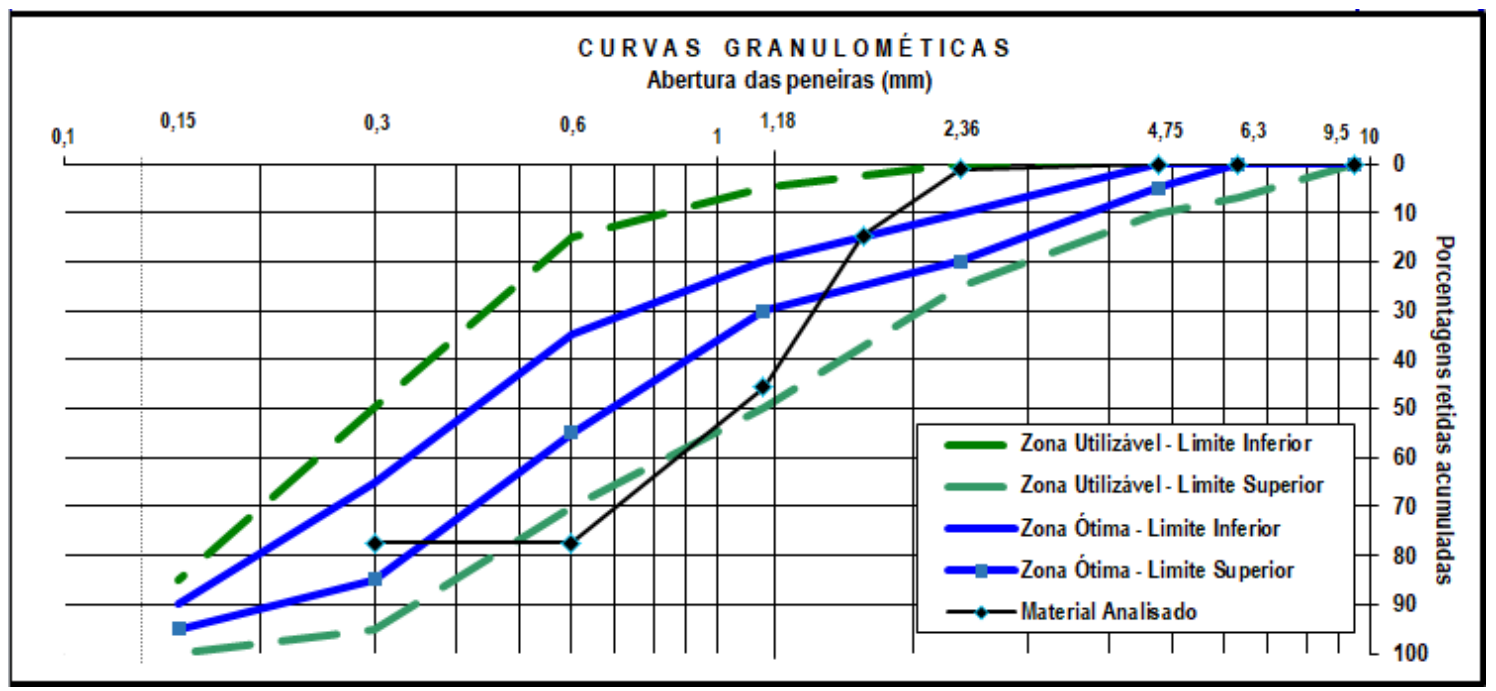

FIGURA 8: Curva Granulométrica do Agregado miúdo Areia - Zona Utilizável FONTE: Elaborada pelo Autor, 2019. 


\begin{tabular}{cc}
\multicolumn{2}{c}{ TABELA 3: Classificação da areia. } \\
\hline Módulo de Finura (da Média) & 2,22 \\
\hline Dimensão Máxima Característica & $2,38 \mathrm{~mm}$ \\
\hline Classificação do Agregado (2005) & Zona Ótima Limites Superiores \\
\hline Classificação do Agregado (1983) & Areia Média (Zona 3) \\
\hline
\end{tabular}

FONTE: Elaborada pelo Autor, 2019.

\subsubsection{Determinação da Composição}

Granulométrica - Agregado Miúdo Pó de Pedra

A Figura 9 representa a curva granulométrica do pó de pedra, onde ele se enquadra nos limites da zona ótima limites inferiores para agregados miúdos.

A Tabela 4 apresenta características físicas do pó de pedra e sua classificação. Ele possui módulo de finura de 1,45 e dimensão máxima de $2,38 \mathrm{~mm}$.

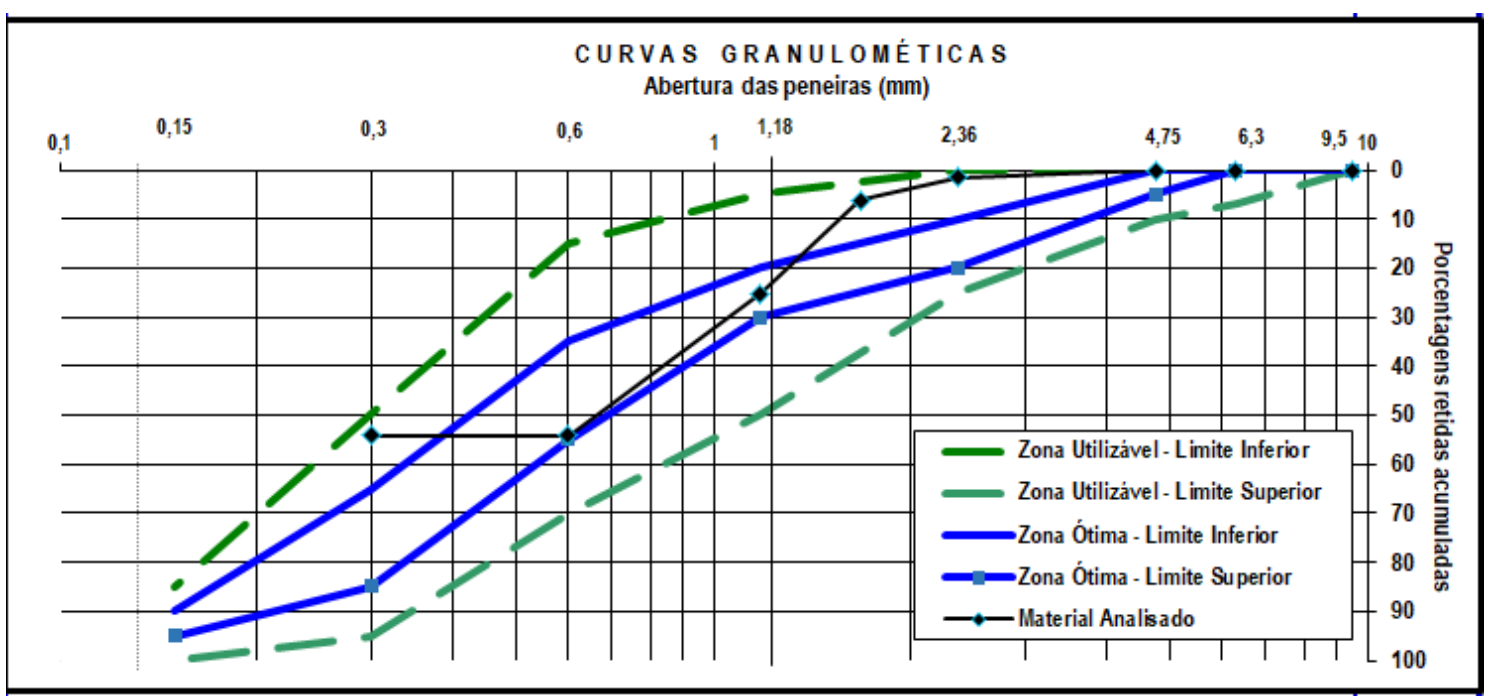

FIGURA 9: Curva Granulométrica do Agregado miúdo Pó de Pedra - Zona Utilizável FONTE: Elaborada pelo Autor, 2019.

\section{TABELA 4 - Classificação da areia.}

\begin{tabular}{cc} 
Módulo de Finura (da Média) & 1,45 \\
\hline Dimensão Máxima Característica & $2,38 \mathrm{~mm}$ \\
\hline Classificação do Agregado (2005) & Zona Ótima Limites Inferiores \\
\hline Classificação do Agregado (1983) & Pó de Pedra Muito Fina (Zona 1) \\
\hline
\end{tabular}

FONTE: Elaborada pelo Autor, 2019. 


\subsubsection{Determinação da Composição}

Granulométrica - Agregado Miúdo Lama

Abrasiva

A Figura 10 representa a curva granulométrica da lama abrasiva, onde ele se enquadra abaixo da classificação de zona ótima limites inferiores para agregados miúdos.

A Tabela 5 apresenta características físicas da lama abrasiva e sua classificação. A lama abrasiva possui módulo de finura de 0,01 e dimensão máxima de 1,68 mm.

\subsubsection{Determinação da Composição Granulométrica - Agregado Graúdo Pedrisco}

A Figura 11 apresenta a curva granulométrica do agregado graúdo Pedrisco.

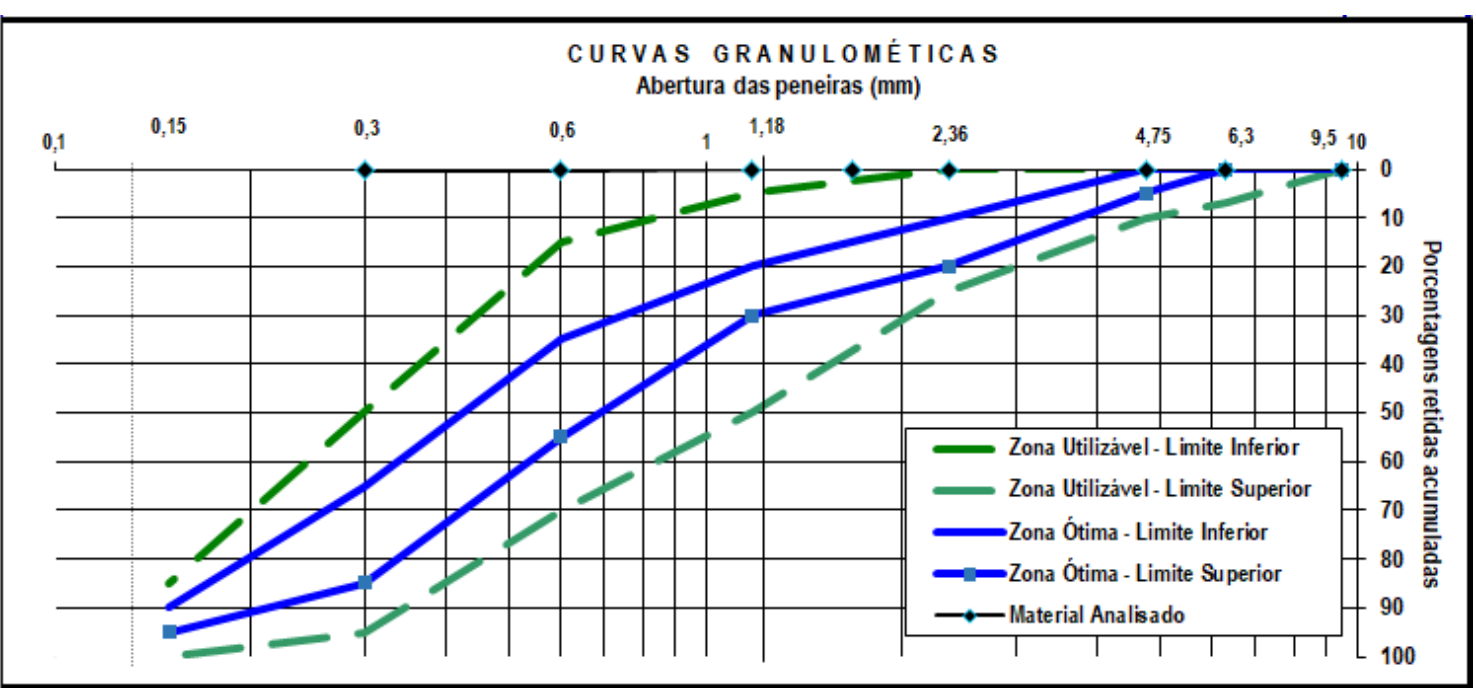

FIGURA 10: Curva Granulométrica do Agregado miúdo Lama Abrasiva - Zona Utilizável FONTE: Elaborada pelo Autor, 2019.

\begin{tabular}{cc}
\multicolumn{2}{c}{ TABELA 5: Classificação da areia. } \\
\hline Módulo de Finura (da Média) & 0,01 \\
\hline Dimensão Máxima Característica & $1,68 \mathrm{~mm}$ \\
\hline Classificação do Agregado (2005) & Abaixo da Classificação: \\
& Zona Ótima Limites Inferiores \\
\hline Classificação do Agregado (1983) & Abaixo da classificação: \\
& Muito Fina (Zona 1)
\end{tabular}

FONTE: Elaborada pelo Autor, 2019. 


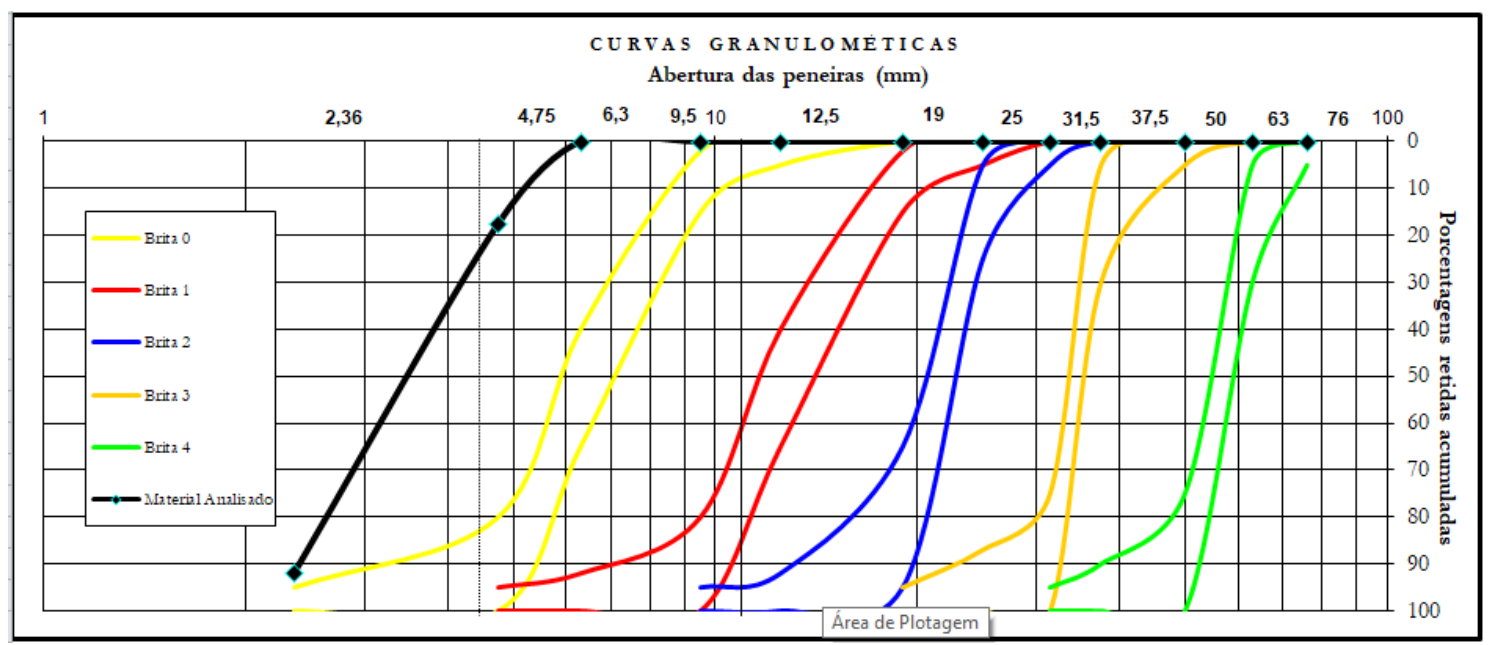

FIGURA 11: Determinação da Composição Granulométrica- Agregado Graúdo Brita FONTE: Elaborada pelo Autor, 2019.

\section{TABELA 6: Classificação da Brita.}

Módulo de Finura (da Média)

Dimensão Máxima Característica

Classificação do Agregado (2005)

Classificação do Agregado (1987)
3,08

$4,75 \mathrm{~mm}$

Agregado Graúdo - Zona 4,75 / 12,5

Abaixo da Classificação:

Agregado Graúdo - Brita 0

FONTE: Elaborada pelo Autor, 2019. 


\subsection{PRODUÇÃO DAS PEÇAS}

\subsubsection{Peças de concreto (Pavers)}

Foram produzidos 120 blocos no laboratório de Materiais de Construção Civil da Faculdade Integradas de Aracruz - FAACZ, 60 blocos foram utilizados para cálculos de índice de absorção da água, a outra metade foi utilizada para ensaios de resistência característica à compressão. Os resultados destes ensaios são discutidos no Capítulo 4. Destaca-se que, para cada uma das condições analisadas neste estudo foram moldados 12 corpos de prova.

\subsubsection{Composições estudadas para produção dos} pavers

Para o desenvolvimento deste trabalho adotou-se como método a substituição de determinadas quantidades do componente pó de pedra pela lama abrasiva, de um traço padrão estabelecido com o uso dos materiais naturais.

Dessa forma, a primeira etapa do trabalho foi à definição de um traço padrão para comparação dos resultados. A partir deste foi incorporado o material alternativo estudado (resíduo gerado no desdobramento de rochas ornamentais), em proporções de 5\%, 10\% 15\% $20 \%$. Consequentemente foi possível a comparação entre os resultados de resistência à compressão do traço padrão com os traços obtidos com a substituição da lama.

\subsection{ENSAIO DE RESISTÊNCIA CARACTERÍSTICA À COMPRESSÃO}

A resistência à compressão da peça, expressa em (MPa), é obtida multiplicando o valor da carga de ruptura, expressa tonelada força (tf), por 9,8 , visto que $1 \mathrm{tf}$ equivale a $9,8 \mathrm{kN}$. O valor encontrado é dividido área de carregamento, expressa em centímetros quadrados $\left(\mathrm{cm}^{2}\right)$, em seguida basta multiplicar o resultado por 10 que terá o valor em MPa. Posteriormente multiplica-se o resultado pelo fator $p$, função da altura da peça, conforme Tabela 7.

\section{TABELA 7: Fator multiplicativo $p$}

\begin{tabular}{cc}
$\begin{array}{c}\text { Espessura nominal } \\
\text { da peça }(\mathbf{m m})\end{array}$ & $\mathbf{p}$ \\
\hline 60 & 0,95 \\
\hline 80 & 1,00 \\
\hline 100 & 1,05 \\
\hline FONTE: NBR 9781:2013
\end{tabular}

A Figura 12 mostra a prensa usada na realização dos ensaios de compressão.

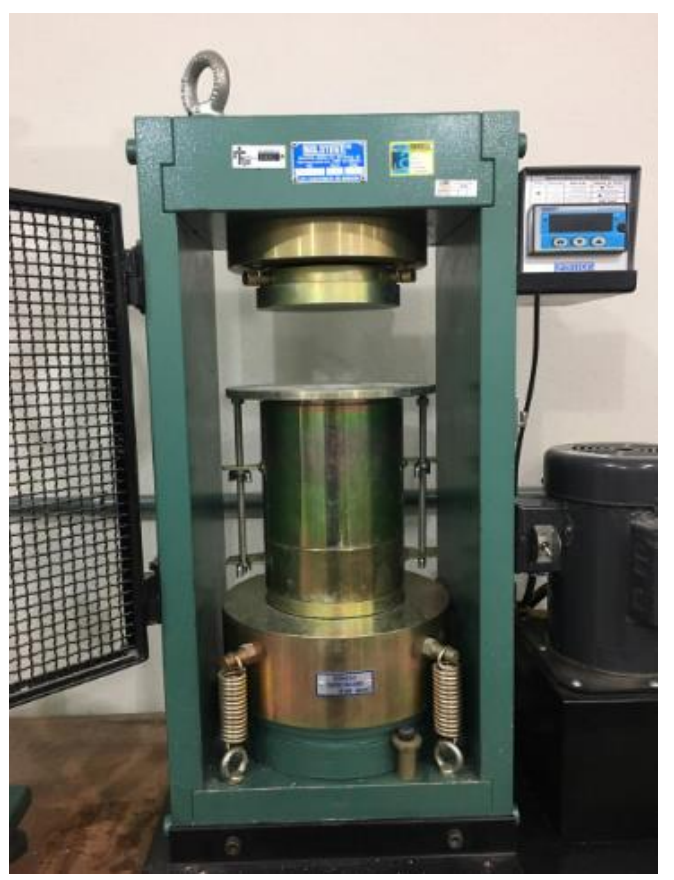

FIGURA 12: Máquina usada nos ensaios de compressão FONTE: Elaborada pelo Autor, 2019. 


\section{RESULTADO E DISCUSSÕES}

\subsection{RESULTADOS DOS ENSAIOS DE RESISTÊNCIA A COMPRESSÃO}

\subsubsection{Resultados dos ensaios de Compressão} simples aos 7 dias

A Figura 13 mostra os resultados da resistência à compressão simples dos pavers aos 7 dias.

\subsubsection{Resultados dos ensaios de Compressão simples aos 14 dias}

A Figura 14 mostra os resultados da resistência à compressão simples dos pavers aos 14 dias.

\subsubsection{Resultados dos ensaios de Compressão simples aos 28 dias}

A Figura 15 mostra os resultados da resistência à compressão simples dos pavers aos 28 dias.

Analisando as Figuras 13, 14 e 15 observa-se que a substituição com a lama abrasiva promoveu o aumento dos valores de resistência à compressão se comparado ao Traço Padrão. Observamos que a lama abrasiva na proporção de 15\%, nesse caso no Traço 3 foi responsável pela maior resistência, tendo uma queda não muito significativa no traço 4 com $20 \%$ de lama abrasiva.

4.1.4 Comparação entre os resultados de Compressão simples aos 7 e aos 28 dias - efeito do tempo de cura

Este item trata-se da comparação entre os resultados dos ensaios aos 7 e aos 28 dias. Desse modo avaliamos o efeito do tempo no processo de cura sobre a resistência mecânica dos pavers produzidos com cada um dos traços estudados.

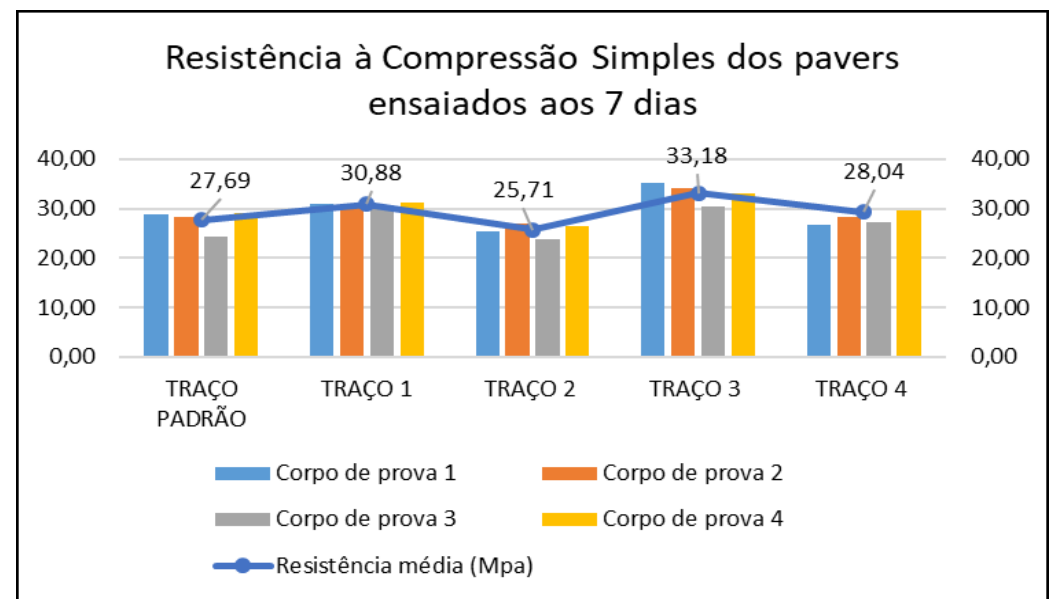

FIGURA 13: Resistência à compressão simples dos pavers ensaiados aos 7 dias FONTE: Elaborada pelo Autor, 2019. 


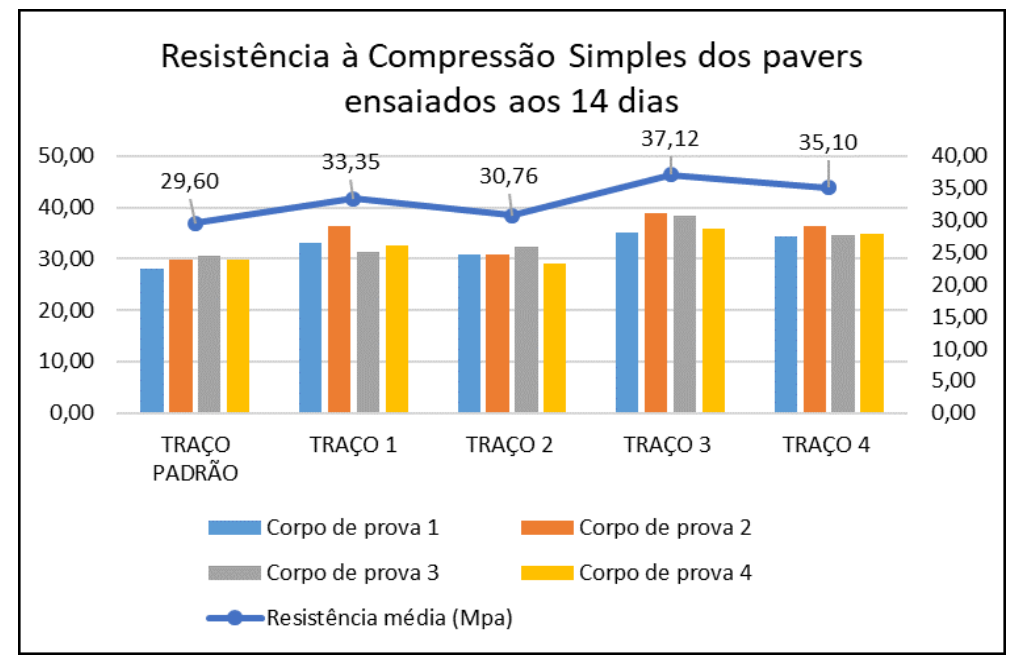

FIGURA 14: Resistência à compressão simples dos pavers ensaiados aos 14 dias FONTE: Elaborada pelo Autor, 2019.

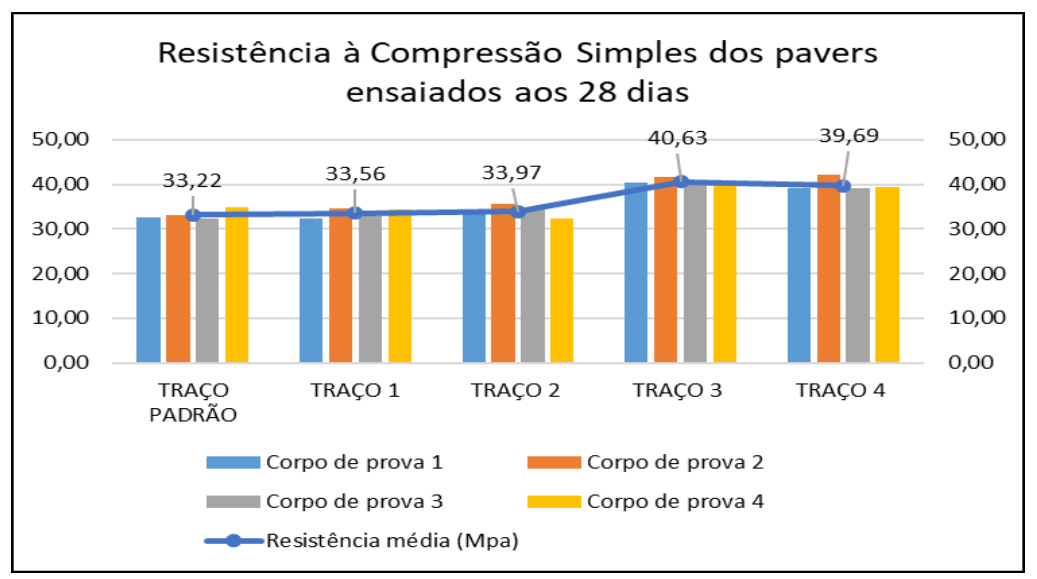

FIGURA 15: Resistência à compressão simples dos pavers ensaiados aos 28 dias FONTE: Elaborada pelo Autor, 2019.

\section{Comparação entre os resultados de Resistência à Compressão simples aos 7 e aos 28 dias}

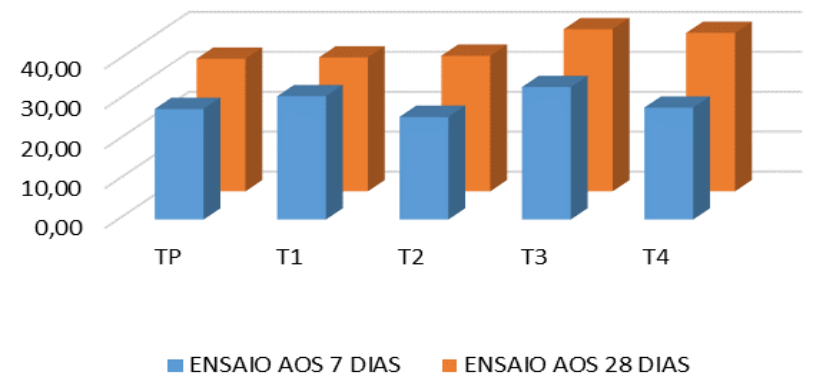

FIGURA 16: Comparação entre os resultados de Compressão simples aos 7 e aos 28 dias - efeito do tempo de cura Fonte: Elaborada pelo Autor, 2019. 
Barbosa et al. (2013), Alves (2008) e Binici et al. (2008) estudaram a fabricação de concreto utilizando rejeito de granito incorporado ao cimento, os resultados demonstraram que além de não ter comprometido a estrutura física dos materiais obtidos, a incorporação da lama tem como vantagem o aumento da resistência à compressão dos produtos.

\subsubsection{Comparação dos resultados de Resistência a Compressão com às especificações das normas}

No referencial teórico foi apresentado às especificações de resistência à compressão de diferentes normas. Neste item são comparados os resultados obtidos com as especificações destas normas, aplicadas em diferentes países.

As especificações de resistência à compressão usualmente são estabelecidas para períodos de cura de 28 dias. Assim, para efeito de comparação usaremos apenas os dados alcançados aos 28 dias. Conforme a Tabela 20 o Traço Padrão, Traço 1 (5\% de lama abrasiva) e Traço 2 (10\% de lama abrasiva) enquadraram-se nas Normas Australiana e Africana, já o Traço 3 (15\% de lama abrasiva) e o Traço 4 (20\% de lama abrasiva) alcançaram além das Normas Australiana e Africana também a Norma Brasileira, que exige no mínimo $35 \mathrm{MPa}$ para tráfego de pedestres, veículos leves e veículos comerciais de linha.

\begin{tabular}{ccc} 
& \multicolumn{2}{c}{ TABELA 8: Especificações da norma para avaliação mecânica de paver. } \\
País & Norma & Parâmetro \\
\hline Brasil & NBR 9780:1987 & Resistência à compressão $\geq 35 \mathrm{MPa}$ \\
\hline Austrália & AS/NZS 4456.4:2003 & Resistência à compressão $\geq 25 \mathrm{MPa}$ \\
\hline África do Sul & SANS 1058:2009 & Resistência à compressão $\geq 25 \mathrm{MPa}$ \\
\hline Canadá & CSAA23.2- 95:1995 & Resistência à compressão $\geq 50 \mathrm{MPa}$ \\
\hline EUA & ASTMC936:1996 & Resistência à compressão $\geq 55 \mathrm{MPa}$
\end{tabular}

TABELA 9: Comparação dos resultados de ensaio de Resistência à Compressão aos 28 dias com as Normas.

\begin{tabular}{ccc} 
Traço & Resistência Média $\mathbf{- 2 8}$ dias & Enquadra na Norma \\
\hline Padrão & $33,22 \mathrm{MPa}$ & Australiana e Africana \\
\hline Traço 1 & $33,56 \mathrm{MPa}$ & Australiana e Africana \\
\hline Traço 2 & $33,97 \mathrm{MPa}$ & Australiana e Africana \\
\hline Traço 3 & $40,63 \mathrm{MPa}$ & Brasileira, Australiana e Africana \\
\hline Traço 4 & $39,69 \mathrm{MPa}$ & Brasileira, Australiana e Africana \\
\hline & \multicolumn{2}{c}{ FONTE: Elaborada pelo Autor, 2019. }
\end{tabular}




\section{CONCLUSÃO}

Tendo em vista os aspectos observados, a incorporação da lama abrasiva na confecção de pavers intertravados de concreto superou o valor mínimo exigido pela NBR 9781:2013 Peças de concreto para pavimentação - Especificação e métodos de ensaio (tráfego de pedestres, veículos leves e veículos comerciais de linha), onde o traço com maior adição de rejeito alcançou aos 28 dias de idade uma resistência à compressão de 39,69MPa.

Além de ser uma alternativa de reutilização desse rejeito de forma verde contrapondo-se seu descarte sem qualquer benefício ao meio ambiente, a lama abrasiva aumentou $6,47 \mathrm{MPa}$ da resistência dos blocos comparado com o traço padrão utilizado.

A utilização de pavimento intertravados de concreto tem grandes vantagens, visto que esses pisos possuem a função de resistir e distribuir ao subleito os esforços aplicados sobre eles, além de melhorar as condições de rolamento e segurança. Dentre essas e outras vantagens, com a adição do rejeito abrasivo no pavers o custo dele diminuiria, dado que as empresas produzem em grande escala este material e precisam descartar ele de forma correta.

\section{REFERÊNCIAS BIBLIOGRÁFICAS}

AMADEI, D. I. B. Avaliação de blocos de concreto para pavimentação produzidos com resíduos de construção e demolição do Município de Juranda/PR. 153p. Dissertação (Mestrado) - Universidade Estadual de Maringá. Departamento de Engenharia Civil. Programa de Pós-Graduação em Engenharia Urbana. Maringá, 2011.

Associação Brasileira de Normas Técnicas (ABNT). NBR 9781:2013. Peças de concreto para pavimentação Especificação e métodos de ensaio. Rio de Janeiro: ABNT, 2013.

BALDO, José Tadeu. Pavimentação Asfáltica: materiais, projeto e restauração. São Paulo: Oficina de Textos, 2007.
KNAPTON, J. "Romans and Their Roads - The Original Small Element - Pavement Technologists". 5th International Concrete Block Paving Conference, TelAviv, Israel, 1996.

BERNUCCI, L. B.; MOTTA, L. M.; CERATTI, J. A. P.; SOARES, J. B. Pavimentação Asfáltica: Formação Básica

para Engenheiros. 1. ed. Rio de Janeiro, RJ. 2006.

BITTENCOURT, S. F. Avaliação da resistência à compressão de pavers produzidos com agregados de resíduos de construção e demolição e areia de fundição. Dissertação (Mestrado) - Tecnologia e Inovação, Faculdade de Tecnologia da Universidade Estadual de Campinas, Limeira, 2012.

COELHO, M. A. M.; TRISTÃO, F. A.; ALVEZ, A. N.; PREZOTTI, J.; PINTO, R.C.D.G. Utilização do Resíduo do Beneficiamento de Rochas Ornamentais (RBRO) em substituição à argila em argamassas. Cerâmica, São Paulo, 2007

CRUZ, Luiz M. Pavimento intertravado de concreto: estudo dos elementos e métodos de dimensionamento. 2003, 281 f. Dissertação (Mestrado) - Mestrado em Ciências em Engenharia Civil, Universidade Federal do Rio de Janeiro, Rio de Janeiro, 2003.

FIORITI, Cesar F. Pavimentos intertravados de concreto utilizando resíduos de pneus como material alternativo. 2007.

LEITE, R. Guia Orientativo do Serrador de Granito. Sinto Brasil Produtos Limitada. Rer. 03/06.

MATTOSO, Adriana Q. O caminho do ouro em Paraty e sua paisagem. Rio de Janeiro, 2009. Disponível em: <http://www.pagem.uerj.br/textos/172_2009/ docs/C\%F3digos\%20e\%20Leis\%20-

$\% 20$ Paraty/IPHAN/proposta\%20-

\%20paraty\%20patrimonio.pdf>

PORTLAND, Associação Brasileira de Cimento. Manual de Pavimento Intertravado: Passeio Público. Associação Brasileira de Cimento Portland - ABCP, São Paulo, 2010. 36p.

SILVA, S. A. C. Caracterização do resíduo da serragem de blocos de granito: Estudo do potencial de aplicação na fabricação de argamassa de assentamento de tijolos de solo-cimento. Dissertação (Mestrado em Engenharia Ambiental) - Universidade Federal do Espírito Santo, Vitória, ES, 1998, apud BRANDÃO, K. C.; RIBEIRO, R. L. P. 
Análise Ambiental de Blocos Cerâmicos Fabricados a partir da lama abrasiva proveniente do beneficiamento do mármore e do granito. Monografia (Graduação) - Instituto Federal do Espírito Santo, Vitória, 2007.

SOUZA, J. N.; RODRIGUES, J. K. G. ; NETO, P. N. DE S.; Utilização dos Resíduos Provenientes da Serragem de Rochas Graníticas como Material de Enchimento em Concretos Asfaltos Usinados a Quente. Disponível: www.ambientebrasil.com.br. Acesso em 05 fev. 2019

WIEBbelling, O. G. Paula. Pavimento com blocos intertravados de concreto: Estudo de caso na UNIVATES. 2015. 73 p. Monografia - Engenharia Civil. Centro Universitário UNIVATES. Lajeado, 2015. 